\title{
MANAGING DISRUPTIONS AND DISTURBANCES ON RAILWAY SERVICES: A REAL-SCALE CASE STUDY
}

\author{
A. PLACIDO ${ }^{1}$, C. PETITO ${ }^{2}$, M. GALLO ${ }^{3} \&$ L. D'ACIERNO ${ }^{4}$ \\ ${ }^{1}$ D'Appolonia S.p.A., Italy \\ ${ }^{2}$ Rete Ferroviaria Italiana (Italian Railway Network), Italy \\ ${ }^{3}$ Department of Engineering, University of Sannio (Benevento), Italy \\ ${ }^{4}$ Department of Civil, Architectural and Environmental Engineering, Federico II University of Naples, Italy
}

\begin{abstract}
In the case of conventional rail lines, when disruptions occur, dispatchers have the difficult task of finding feasible rescheduling solutions rapidly so as to re-establish ordinary conditions as soon as possible. Despite the numerous contributions for automatic rescheduling proposed in the literature, this process is still totally controlled by dispatchers who decide according to their personal experience and under their own responsibility. Indeed, in many cases, it can be more advantageous to let the system revert to ordinary conditions without implementing any strategy rather than look for solutions which can reduce the discomfort perceived by passengers. In this article we propose a system of models for managing the rail system, combining a microscopic simulation model with an assignment tool which is able to consider passenger flows on the network. As a result, the disutility experienced by users during their trip can be evaluated and feasible intervention strategies can be assessed, taking into account the passengers' perspective. An application on a real regional line in Campania (Italy) shows the benefits of the proposed approach for performing off-line analyses of intervention solutions and helping dispatchers make decisions during critical events to increase service quality.

Keywords: Public transport management, rail network micro-simulation, real-scale network analysis, travel demand estimation.
\end{abstract}

\section{INTRODUCTION}

From a user point of view, one of the main strengths of rail transport systems is reliability, that is the ability to respect timetables and travel times. However, disruptions or disturbances to planned services can occur for several reasons (stochastic fluctuations of travel demand, infrastructure damage, convoy breakdowns, etc.), causing significant reductions in the level of service. Hence, one of the aims of the rail network operator is to minimize the duration of such disruptions and their negative effects. Indeed, when several different interventions can be applied to restore the usual service conditions, the operator is generally unable to evaluate rapidly the best for satisfying user needs, due to the lack of codified strategies for each anomaly. Even if there may be a large number of scenarios of possible disruption on a railway line, a preventive examination of some of them so as to identify the most effective solutions can help decision-makers to find the best restoring solution.

In this article, we propose a general procedure for evaluating the countermeasures that can be proposed for minimizing effects of disruptions and disturbances on the service from the point of view of the users; the general procedure is tested on a real-scale case study. In real contexts, the application of the proposed procedure to several common/probable disruption scenarios requires building a database of possible interventions able to help operators to take the best decisions to limit users' discomfort; indeed, due to huge calculation times, since the decision has to be taken as soon as possible, there is no time to apply the procedure after the disruption occurs.

In the literature, the study of disturbances and disruptions in railway contexts can be found in Cacchiani et al. [1], D'Ariano and Albrect [2], D'Ariano et al. [3], D'Ariano [4], 
and Goverde [5, 6]. Some possible restoring interventions were proposed by Corman et al. [7-9], D'Ariano et al. [10-11], Mascis and Pacciarelli [12], and Quaglietta et al. [13]. The importance of considering user demand in the problem was highlighted by Canca et al. [14-15], D'Acierno et al. [16], Hamdouch et al. [17], Kanai et al. [18] and Zheng et al. [19]. Finally, effects of information systems on user behaviour and related quality perceptions were investigated by Bifulco et al. [20], Dziekan and Kottenhoff [21], Molina and Timmermans [22] and Paulley et al. [23].

This article is organized as follows: Section 2 focuses on the problem and the mathematical models and algorithms that can be adopted to simulate the whole network; Section 3 applies the proposed approach in the case of a real network; finally, conclusions and research perspectives are summarized in Section 4.

\section{PROBLEM, MODELS AND ALGORITHMS}

The main assumption adopted in the proposed approach is that all features of the analysed rail network (lengths, slopes, curvature radiuses, signalling systems, etc.) and related service parameters (rolling stock, timetables, etc.) are known. Our analyses are based on the hypothesis that a disruption or a disturbance occurs on the network and the operator has to intervene to minimize the impacts on the service and, in particular, on users. Indeed, operators generally intervene only on the basis of their own experience; if a database of feasible interventions for each kind of disruption/disturbance was available, they could find a codified solution to apply. On the contrary, if the disruption/disturbance did not belong to the database, it would be examined afterwards for possible inclusion, and operators would be forced to intervene based only on their experience.

In this article we propose a general procedure for building the database of disruptions/ disturbance and the corresponding possible interventions, with the objective of minimizing user generalized costs. Moreover, this database can be further updated and expanded when a new (hitherto not considered) disruption or disturbance occurs.

First of all, we have to be able to simulate the undisturbed scenario, US, in a different time period, $h$, in order to estimate the related generalized user costs, $u g c^{h}$, in normal conditions; the results of these simulations will be used as baselines. For each time period, $h$, the procedure for estimating the generalized user costs is reported in Fig. 1. The procedure consists in (a) implementing a supply model, in terms of infrastructures including signalling systems $\left(\boldsymbol{I}^{h}\right)$, rolling stock $\left(\boldsymbol{R} \boldsymbol{S}^{h}\right)$ and timetables $\left(\boldsymbol{T} \boldsymbol{T}^{h}\right)$; (b) estimating the origin-destination matrix $\left(\boldsymbol{O} \boldsymbol{D}^{h}\right)$ representing the transportation demand that uses the services; (c) a simulation model that is able to estimate the performances (actual headways and running times indicated as $\boldsymbol{H} \boldsymbol{R} \boldsymbol{T}^{h}$ ) of the services on the rail network; (d) an assignment model and algorithm which, as a function of the supply model, demand and performances of the services, are able to estimate the user flows $\left(f^{h}\right)$ on the network. The output of the procedure consists in the user generalized costs $\left(u g c^{h}\right)$. The same procedure can be used for estimating user generalized costs in the case of disruption/disturbance scenarios and related restoring strategies.

Service performance is calculated by adopting a simulation model based on a 'micro' approach (details on simulation models can be found in Hansen \& Pachl [24]) since (i) we need a high level of detail for simulating the effects of disruptions/disturbances on users and (ii) we have to simulate the network dynamically, considering the evolution of traffic conditions after the occurrence of disturbances to the service. Indeed, disruption/disturbance events produce dynamic phenomena which cannot be analysed statically, and therefore it is necessary to adopt a micro-simulation (MS) approach. 


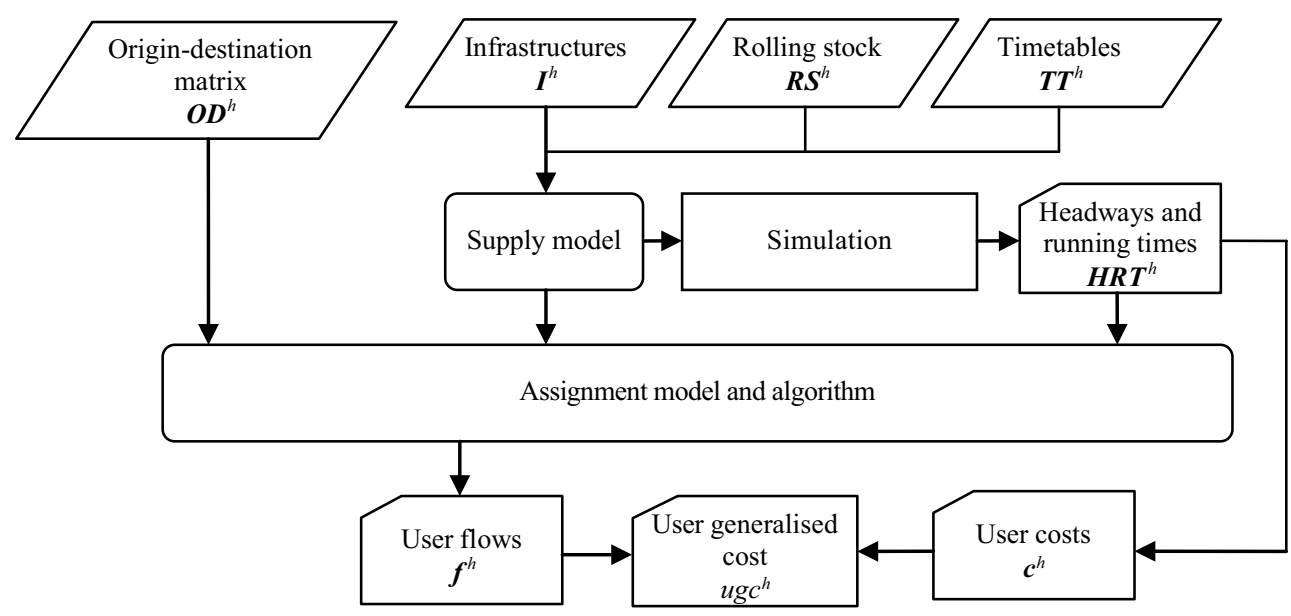

Figure 1: Procedure for estimating the user generalized costs for each time period.

In this article, we propose to adopt OPENTRACK ${ }^{\circledR}$ software (Nash \& Huerlimann [25]) as a MS tool within the procedure. This software allows us to build the supply model to a high level of detail and simulate the operation of services dynamically. Moreover, the software gives the possibility to manage and modify input and output values (e.g. timetables, simulation results, dwell times) by importing/exporting txt files. Thus, other tools can be easily combined with OpenTRACK ${ }^{\circledast}$, allowing its potential to be extended. Formally, the MS model can be written as follows:

$$
\boldsymbol{H R} \boldsymbol{T}^{h}=\boldsymbol{M S}\left(\boldsymbol{I}^{h}, \boldsymbol{R} \boldsymbol{S}^{h}, \boldsymbol{T} \boldsymbol{T}^{h}\right) \quad \forall h
$$

As regards the assignment, D'Acierno et al. [26] proposed to split the interaction between travel demand and transportation systems into two different models: a pre-platform model (PPM) and an on-platform model (OPM). The PPM estimates the number of passengers arriving at each station in time period $h$ while the OPM assigns these passengers to the trains operating in the same time period, considering explicitly capacity limits of rail convoys as well as the resulting interaction with the service. In the following, we assume that the results of the PPM are known and only the results of the OPM will be considered affected by different scenarios. Indeed, our proposal is to simulate impacts of disruptions/disturbances on user travel times without considering possible effects on modal split or on total travel demand.

In particular, the OPM analyses, for each train approaching a station, whether the residual capacity exceeds the number of boarding passengers. If this condition is not satisfied, it is necessary to distinguish between two possible contexts. In the first case, that is in the case of high-frequency services (e.g. similar to a metro line), only the portion of travel demand (i.e. waiting passengers) equal to the residual capacity is able to board the train while the surplus waits for the following trains. In the second case, that is in the case of low-frequency services (e.g. one train per hour or less), since waiting for a following train could require unfeasible waiting times, passenger could be forced to abandon the rail system and adopt a different transportation mode. Hence, in this second case, it is necessary to adopt feasible strategies to avoid users waiting on the platform for a following convoy should the capacity of the train be reached (a very seldom event on conventional lines) or if the line is interrupted. 
Formally, the OPM can be formulated as:

$$
\left(\boldsymbol{f}^{h}, \boldsymbol{c}^{h}\right)=\boldsymbol{O P M}\left(\boldsymbol{I}^{h}, \boldsymbol{R} \boldsymbol{S}^{h}, \boldsymbol{T} \boldsymbol{T}^{h}, \boldsymbol{O D}^{h}, \boldsymbol{H R} \boldsymbol{T}^{h}\right) \quad \forall h
$$

where $f^{h}$ is the user flow vector and $\boldsymbol{c}^{h}$ the user cost vector. Details on the OPM function, which expresses the implementation of the OPM model, can be found in D'Acierno et al. [26].

In a cost-benefit analysis, it is necessary to monetize any improvement (benefit) or discomfort (cost) in order to compare them with intervention (or non-intervention) costs. Hence, it is necessary to calculate, for each analysed scenario, the user generalized cost which expresses a weighted sum of times and costs incurred by users during their trips. However, in the case of intervention strategies which do not provide any variation in user costs (such as in the case of ticket refunds for excessive delays), monetary terms may be omitted, leaving in the formulation only time terms which have to be monetized in order to compare them with intervention costs. In these contexts, the effects of strategies that we assume measured by means of the user generalized costs (i.e. $u g c^{h}$ ) can be calculated as follows:

$$
u g c^{h}=\sum_{i} \beta_{V O T}^{i} \cdot\left(\beta_{\text {waiting }}^{i} \cdot \sum_{s} \sum_{p} \sum_{r} t w_{s, p}^{i, r, h} \cdot f w_{s, p}^{i, r, h}+\beta_{\text {on-board }}^{i} \cdot \sum_{l} \sum_{r} t b_{l}^{i, r, h} \cdot f b_{l}^{i, r, h}\right)
$$

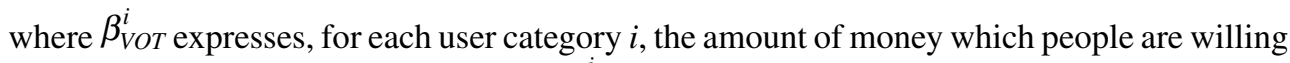
to spend to save one hour of travel time; $\beta_{\text {waiting }}^{i}$ is a parameter which expresses the importance (i.e. relative weight) attached to waiting times by users belonging to category $i ; t w_{s, p}^{i, r, h}$ is the average waiting time of user category $i$ at station $s$ on platform $p$ between run $(r-1)$ and run $r ; f w_{s, p}^{i, r, h}$ is the number of passengers of user category $i$ waiting at station $s$ on platform $p$ between run $(r-1)$ and run $r ; \beta_{\text {on-board }}^{i}$ is a parameter which expresses the importance (i.e. relative weight) attached by users belonging to category $i$ to on-board time and depends on the crowding level within the coach (details on parameter values can be found in MVA Consultancy [27]); $t b_{l}^{i, r, h}$ is the time spent by users of category $i$ on board the rail convoy associated to run $r$ for travelling on link $l ; f b_{l}^{i, r, h}$ is the number of passengers belonging to category $i$ who travel on the rail convoy associated to run $\mathrm{r}$ while crossing link $l$. It is worth noting that terms $t w_{s, p}^{i, r, h}$ and $t b_{l}^{i, r, h}$ are indicated in Fig. 1 as vector $\boldsymbol{c}^{h}$ and terms $f w_{s, p}^{i, r, h}$ and $f b_{l}^{i, r, h}$ are indicated as vector $\boldsymbol{f}^{h}$. Obviously, these terms are calculated, respectively, by means of the MS model and the assignment model (especially the OPM, since we have assumed the PPM as fixed).

It is worth noting that parameters $\beta_{\text {waiting }}^{i}$ and $\beta_{\text {on-board }}^{i}$ express the weight of time components compared to travel time in comfortable conditions (such as travelling by car). For this reason, MVA Consultancy [27] provides term $\beta_{\text {on-board }}^{i}$ increasing (i.e. higher than 1) with coach crowding. However, in the applications we simplified the definition of $\beta_{\text {on-board }}^{i}$ by setting it always equal to 1 . Moreover, in order to avoid any computational problem (i.e. undetermined conditions), we propose to fix parameter $\beta_{V O T}^{i}$ (for instance, to a literature value) so that the only unknown parameter to be determined is $\beta_{\text {waiting }}^{i}$.

With the above formulations, the database of disruptions/disturbances can be initialized in a first phase by adopting a failure model, $F M$, for generating hypothetical failure conditions. This database could then be updated with the disruptions/disturbances that will occur and that do not yet belong to the database, according to the scheme in Fig. 2.

The FM determines the breakdown scenarios which are worth analysing. Indeed, since the proposed procedure is based on an off-line approach, it is necessary to investigate the failure 


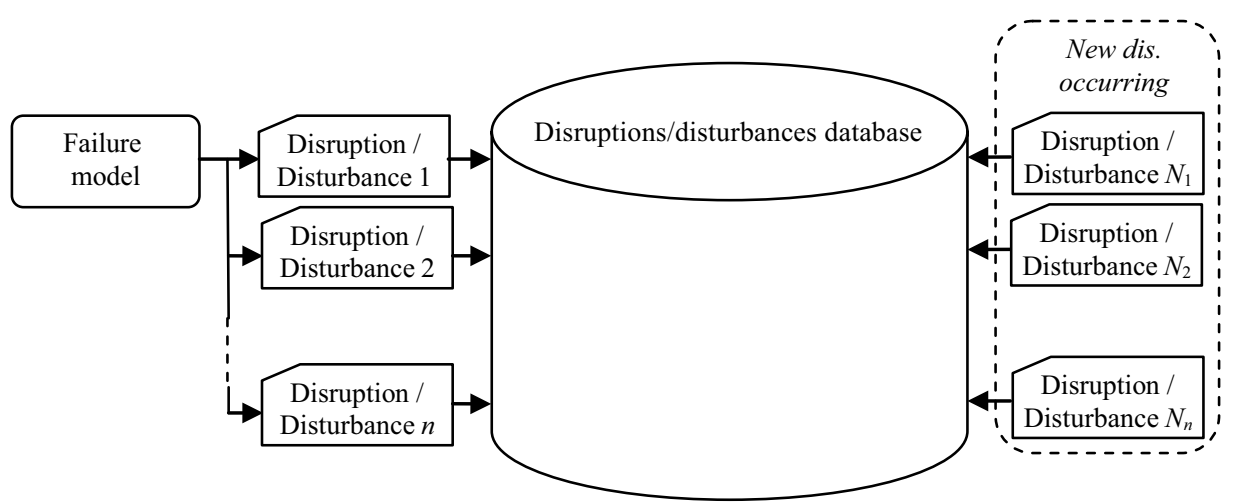

Figure 2: Construction of disruption/disturbance database.

contexts which are likely to happen during the real service. In particular, the FM adopts RAMS (reliability, availability, maintainability and safety) techniques (see, for instance, CENELEC [28]) whose aim is to calculate at any life cycle step and for each component of the system, the expected failure rate and its effects on the service in the event of occurrence. Examples include the interruption of a track section, the reduction in performance of the whole line or part of it, or the unavailability of a rail convoy. The database can also be built only with the historical occurrences of disruptions/disturbances without adopting an FM.

For each defined disruption/disturbance scenario, several countermeasures are tested using the simulation model and the one that minimizes the impacts on users is associated to the scenario. In the future, when the same (or similar) scenario occurs, the operator can find the best countermeasure to apply in the system.

\section{NUMERICAL APPLICATIONS AND RELATED RESULTS}

In order to show its utility and applicability in real cases, the proposed approach was applied on the regional railway line between Formia and Napoli Centrale and its 'Villa LiternoNapoli Gianturco' section, both located in Campania in southern Italy. The line in question, consisting of 26 stations along a total length of $122.34 \mathrm{~km}$ (see Fig. 3), is a vital connection between the city of Naples (indicated in the figure with its Italian name Napoli) and several high-density towns along the coast, including those of the southern part of Lazio, the region north of Campania. It also connects Naples with Rome and is used by highly heterogeneous rail traffic (intercity, regional, metropolitan and freight trains). High-speed trains do not use this infrastructure since there is another line which is exclusive to this kind of rail convoy.

The section between Pozzuoli and Gianturco passes through the city of Naples and is characterized by high-frequency services and short distances between stations. It is therefore considered a metropolitan section, namely Line 2 of the Naples metro system.

The simulated service concerns the ordinary timetable of a weekday from 6:00 to 13:00. This time period covers the morning peak hours during which trains are full of commuters. In all, there are 169 trains divided as follows: 12 intercity trains, 59 regional trains composed of three subcategories and 98 metropolitan trains.

Obviously, each train category serves specific stations according to the planned path. Details about these paths are summarized in Table 1. Moreover, no freight trains run in the simulated period since passenger trains consume all the available capacity. 


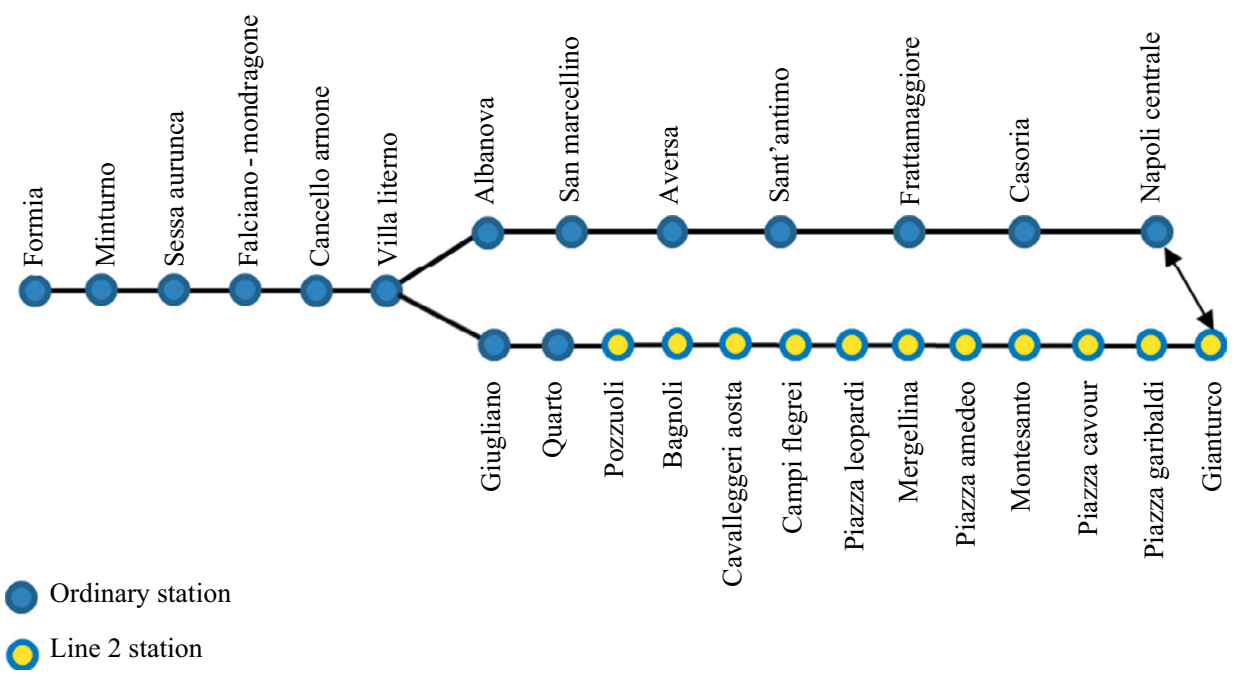

Figure 3: Schematic representation of all stations within the 'Formia-Napoli Centrale' section.

Table 1: List of stations served by each train category.

\begin{tabular}{|c|c|c|}
\hline Service & Path & Stations served \\
\hline Intercity & $\begin{array}{l}\text { Formia-Napoli } \\
\text { Centrale }\end{array}$ & Formia-Aversa-Napoli Centrale \\
\hline Regional type 1 & $\begin{array}{l}\text { Formia-Napoli } \\
\text { Centrale }\end{array}$ & $\begin{array}{l}\text { Formia-Minturno-Sessa Aurunca-Falciano } \\
\text { Mondragone-Villa Literno-Aversa-Napoli Centrale }\end{array}$ \\
\hline Regional type 2 & $\begin{array}{l}\text { Villa Literno- } \\
\text { Napoli Centrale }\end{array}$ & $\begin{array}{l}\text { Villa Literno-Albanova-San Marcellino Frignano- } \\
\text { Aversa-Sant'Antimo-Frattamaggiore-Casoria-Napoli } \\
\text { Centrale }\end{array}$ \\
\hline Regional type 3 & $\begin{array}{l}\text { Formia-Napoli } \\
\text { Gianturco }\end{array}$ & $\begin{array}{l}\text { Formia-Minturno-Sessa Aurunca-Falcinao } \\
\text { Mondragone-Cancello Arnone-Villa Literno- } \\
\text { Giugliano-Quarto-Pozzuoli-Bagnoli-Cavalleggeri } \\
\text { Aosta-Campi Flegrei-Piazza Leopardi-Mergellina- } \\
\text { Piazza Amedeo-Montesanto-Piazza Cavour-Piazza } \\
\text { Garibaldi-Gianturco }\end{array}$ \\
\hline Metropolitan & $\begin{array}{l}\text { Pozzuoli-Napoli } \\
\text { Gianturco }\end{array}$ & $\begin{array}{l}\text { Pozzuoli-Bagnoli-Cavalleggeri Aosta-Campi } \\
\text { Flegrei-Piazza Leopardi-Mergellina-Piazza Amedeo-- } \\
\text { Montesanto-Piazza Cavour-Piazza Garibaldi-Gianturco }\end{array}$ \\
\hline
\end{tabular}

3.1 The definition of failure contexts

As stated in the previous section, the FM provides the failure scenario which has to be simulated. For the sake of simplicity, in this application RAMS analyses are neglected. Such surveys are generally carried out by rail operators and/or manufacturers and failure rates of each component are already available. However, although hypothesized, the simulated failure scenarios are plausible since they are drawn from real occurrences in the past. In particular, 
we considered the interruption of a track section in four different points of the network as follows:

1. a service interruption of two hours (i.e. from 7.00 to 9.00) to the odd track (i.e. direction Formia-Napoli) between the stations of Minturno and Sessa Aurunca;

2. a service interruption of two hours (from 7.00 to 9.00) to the odd track (direction FormiaNapoli) between Casoria and Napoli Centrale;

3. a service interruption of two hours to the odd track (direction Formia-Napoli Gianturco) between the stations of Pozzuoli and Bagnoli;

4. a service interruption of four hours (i.e. from 7.00 to 11.00) of both tracks near Albanova.

For each disrupted scenario, the following test cases were assessed:

- the non-intervention strategy, i.e. the dispatcher waits for the end of the disruption without modifying the planned timetable;

- intervention strategy applied after $30 \mathrm{~min}$ from the occurrence of the failure event;

- intervention strategy applied immediately after the occurrence of the failure event.

It is worth noting that all failure scenarios and related intervention (or non-intervention) strategies have limited time durations. Therefore, we may assume that none of the passengers leaves the rail system, but everyone is waiting to travel. Hence, disruption effects can be expressed in terms of variation in passenger waiting times.

The aim of the application was to demonstrate the importance of reacting as rapidly as possible to minimize the degradation of the service quality during disruptions. Indeed, since no emergency timetables are generally planned by rail operators, dispatchers have to make decisions they will be responsible for based on their personal experience and they sometimes prefer to leave the system without any kind of intervention. By adopting a decision support system such as that proposed in this article, it is possible to determine feasible solutions which can be standardized and implemented in real time in case of necessity.

\subsection{Implementation of the simulation model}

The first step for running the procedure is the microscopic reproduction of the line by means of OPENTRACK ${ }^{\circledR}$ software. For this purpose, the infrastructure was represented with the maximum level of detail in terms of both distances and signalling system. The latter is based on the BACC (i.e. Italian coded track circuit) train spacing system with the addition of the SCMT which is the Italian standard for the ETCS level 1 (for more details on the signalling system see, for instance, Pachl [29]). Furthermore, the Villa Literno-Napoli Gianturco section is based on contra-flow tracks, meaning that trains can be run indifferently on both even and odd tracks without reducing their speed.

As far as the train characteristics are concerned, the whole fleet running on this line comprises seven different train models whose main features adopted for the application of the simulation model and OPM are summarized in Table 2.

However, the simulation model was also developed by considering movements of the rolling stock. Hence the delay of a rail convoy also produces delays in all runs in a day performed by using the same rolling stock. Finally, to simplify the disruption analysis, we do not consider the use of additional rolling stock to reduce delay propagation as an intervention strategy. 
Table 2: Main features of the rolling stock.

\begin{tabular}{lccc}
\hline Rolling stock & $\begin{array}{c}\text { Capacity } \\
(\text { pass. })\end{array}$ & $\begin{array}{c}\text { Max speed } \\
(\mathrm{km} / \mathrm{h})\end{array}$ & $\begin{array}{c}\text { Length } \\
(\mathrm{m})\end{array}$ \\
\hline TAF train (regional double-decker train) & 841 & 14 & 104 \\
Minuetto train (regional train) & 284 & 160 & 52 \\
Regional train & 452 & 140 & 132 \\
Inter-regional train & 520 & 160 & 185 \\
Metropolitan train & 328 & 140 & 102 \\
ETR 450 (i.e. intercity high-speed train) & 390 & 250 & 234 \\
Intercity train (8 coaches) & 504 & 200 & 228 \\
\hline
\end{tabular}

\subsection{Definition of travel demand}

The assignment of travel demand to the service requires the definition of passenger flows arriving at the station prior to the departure of each train. For this specific application, information about the travel demand (i.e. PPM outputs) were obtained from the population census data provided by ISTAT (the Italian National Institute of Statistics). In this way, for each train category, four different matrices were obtained which correspond to different time intervals (before $7: 15,7: 15-8: 15,8: 15-9: 15$, after 9:15). Since it is not possible to obtain detailed mobility information after 9:15, it is assumed that all trains performing the service between 9:15 and 13:00 have the same matrices.

The procedure adopted to obtain these data can be mainly divided into two phases: (a) for each station, the catchment area is determined. Thus, all municipalities served by that station are identified; (b) for each municipality, the number of people who take the train to reach one of the other municipalities served by the other stations on the line can be extracted from the ISTAT database. Information about the four time intervals is also provided. Obviously, this process has to be repeated for each station on the whole line.

Since the adopted procedure provides passenger movements between municipalities, it is not possible to determine detailed information of movements within each district. Hence Line 2 stations (i.e. on the metropolitan line within Naples) are not included in the OD matrix and we assumed that the total number of users travelling within Naples (drawn from the ISTAT database) is equally split between all metro lines of the city. Finally, just three main stations of Line 2 were considered (i.e. Napoli Piazza Garibaldi, Napoli Mergellina and Napoli Campi Flegrei).

\subsection{Interaction between rail service and travel demand}

In order to implement rail system analysis, the OPM (i.e. the interaction between the rail service simulated by OPENTRACK ${ }^{\circledR}$ software and travel demand calculated as shown in the previous subsection) was applied 12 times in order to determine user generalized costs for each of the four failure scenarios in the case of the three different intervention strategies. Obviously, these analyses were compared with the ordinary service condition in order to have an idea of the total generalized cost perceived by users when there are no problems affecting the system. 


\subsubsection{Analysis of the ordinary service}

The ordinary service was simulated by adopting parameter values shown in Table 3 . These values were drawn from previous surveys proposed in the literature (Cascetta [30], Wardman \& Whelan [31]), highlighting the fact that waiting time is generally almost two to three times more burdensome than time spent on board. Moreover, the dwell times at stations are not considered as flow dependent but as constant values (i.e. planned dwell times), meaning that the planned dwell times are sufficient for all passengers to board and alight.

The results obtained by applying OPM are shown in Table 4. The great difference in terms of total cost between the two travel directions is due to the higher attractiveness of Naples, home to universities, several hospitals, offices and banks. The city therefore experiences large commuter flows. However, intercity trains in the opposite direction (i.e. Napoli-Formia towards Rome) are also crowded due to the presence of workers and students travelling towards Italy's capital.

\subsubsection{Analysis of the first disrupted scenario}

The first simulated scenario involves a service interruption of two hours (i.e. from 7.00 to 9.00) to the odd track (i.e. Formia-Napoli direction) between the stations of Minturno and Sessa Aurunca (see Fig. 4), that is before the node of Villa Literno.

In the case of non-intervention, all trains on the odd track are forced to wait for the end of disruption to start their runs again. This causes a propagation of the delay which affects eight consecutive trains and entails a 39.2\% increase in generalized costs (see Table 5).

Table 3: Parameter values of the objective function.

\begin{tabular}{ll}
\hline Parameter & Value \\
\hline$\beta_{\text {waiting }}$ & 2.5 \\
$\beta_{\text {on-board }}$ & 1.0 \\
$\beta_{\text {vOT }}$ & 5.0 euro/hour \\
\hline
\end{tabular}

Table 4: User generalized costs in ordinary conditions.

\begin{tabular}{lcccc}
\hline \multirow{2}{*}{ Direction of travel } & \multicolumn{3}{c}{ Service class } & \multirow{2}{*}{ Total } \\
\cline { 2 - 4 } & Intercity & Regional & Metropolitan & \\
\hline Formia-Napoli & $€ 1,396.85$ & $€ 11,329.06$ & $€ 18,243.22$ & $€ 30,969.13$ \\
Napoli-Formia & $€ 1,878.40$ & $€ 2,490.36$ & $€ 13,201.20$ & $€ 17,569.96$ \\
\hline
\end{tabular}

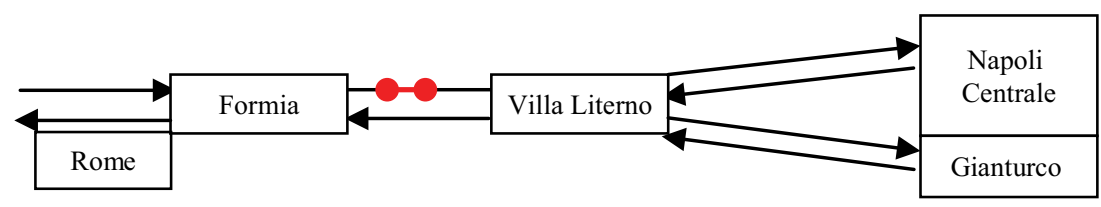

Figure 4: Graphic representation of the Scenario 1 failure. 
Table 5: User generalized costs: Scenario 1 without any intervention strategy.

\begin{tabular}{lcccc}
\hline \multirow{2}{*}{ Direction of travel } & \multicolumn{3}{c}{ Service class } & \multirow{2}{*}{ Total } \\
\cline { 2 - 4 } & Intercity & Regional & Metropolitan & \\
\hline Formia-Napoli & $€ 3,593.59$ & $€ 20,292.75$ & $€ 25,887.24$ & $€ 49,773.58$ \\
Napoli-Formia & $€ 1,878.40$ & $€ 2,706.51$ & $€ 13,201.20$ & $€ 17,786.11$ \\
\hline
\end{tabular}

In particular, trains on the even track (i.e. Villa Literno-Formia direction) are not influenced by the disruption since they can continue to run without any interruption.

Therefore, the first intervention strategy (based on the assumption that dispatchers wait 30 min before applying the strategy) is to enable the trains on the odd track to use the even track alternately. In particular, since this section of the line is not based on contra-flow tracks, the trains heading towards Napoli Centrale have a speed restriction of $90 \mathrm{~km} / \mathrm{h}$. Upon analysing the results, it emerges that, due to the alternate circulation, both directions are affected by delay (see Table 6). However, delays are notably lower than the previous case, that is only $+8.3 \%$ with a reduction of $30.9 \%$. Indeed, passengers travelling on the odd track experience a lower disutility while users travelling in the opposite direction undergo a slight increase in costs.

Finally, the last strategy consists in enabling alternate circulation immediately after breakdown occurrence. As expected (see Table 7), delay propagation in both directions is lower than in the previous cases, which results in calming the negative effects of the disruption more rapidly. In this case, the increase in user generalized costs is just $4.1 \%$ higher than under ordinary service conditions (i.e. 35.1\% lower than with respect to the non-intervention strategy).

Table 6: User generalized costs: Scenario 1 with the first intervention strategy.

\begin{tabular}{lcccc}
\hline \multirow{2}{*}{ Direction of travel } & \multicolumn{3}{c}{ Service class } & \multirow{2}{*}{ Total } \\
\cline { 2 - 4 } & Intercity & Regional & Metropolitan & \\
\hline Formia-Napoli & $€ 1,778.38$ & $€ 12,684.36$ & $€ 19,044.51$ & $€ 33,507.25$ \\
Napoli-Formia & $€ 2,475.00$ & $€ 2,509.45$ & $€ 14,060.62$ & $€ 19,045.07$ \\
& & & & $€ 52,522.32$ \\
\hline
\end{tabular}

Table 7: User generalized costs: Scenario 1 with the second intervention strategy.

\begin{tabular}{lcccc}
\hline \multirow{2}{*}{ Direction of travel } & \multicolumn{3}{c}{ Service class } & \multirow{2}{*}{ Total } \\
\cline { 2 - 4 } & Intercity & Regional & Metropolitan & \\
\hline Formia-Napoli & $€ 1,651.95$ & $€ 11,444.52$ & $€ 18,780.51$ & $€ 31,876.98$ \\
Napoli-Formia & $€ 2,345.16$ & $€ 2,908.74$ & $€ 13,412.36$ & $€ 18,666.26$ \\
& & & & $€ 50,543.24$ \\
\hline
\end{tabular}


3.4.3 Analysis of the second disrupted scenario

The second failure scenario (Fig. 5) is based on a service interruption of two hours (from 7.00 to 9.00) to the odd track (Formia-Napoli direction) between Casoria and Napoli Centrale, that is the last part of the line before reaching the main station of the city of Naples.

The non-intervention strategy produces large delays which affect both directions (i.e. the even and odd direction). This is due to the fact that the faulty section is near Napoli Centrale and therefore, because of the interlocking system, some routes are blocked and thus not available, thereby influencing the opposite direction. In this case the increase in user generalized costs is $69.0 \%$ (see Table 8 ).

By enabling alternate circulation $30 \mathrm{~min}$ after the beginning of the disruption (i.e. the first intervention strategy), the benefits to the service are considerable (Table 9), since the increase in generalized costs is $17.9 \%$ (i.e. $51.1 \%$ lower with respect to the non-intervention strategy).

Obviously, the situation further improves if alternate circulation is imposed as rapidly as possible (second intervention strategy). Indeed, as shown in Table 10, both even and odd trains accrue fewer delays, which results in a higher service quality level during the degraded regime with only a $9.7 \%$ increase in generalized costs (i.e. 59.2\% lower than the nonintervention strategy and $8.2 \%$ lower with respect to the first intervention strategy).

\subsubsection{Analysis of the third disrupted scenario}

Contrary to previous simulations which affected the main line between Formia and Napoli Centrale stations, Scenario 3 considers a two-hour service interruption to the odd track (Formia-Napoli Gianturco direction) between the stations of Pozzuoli and Bagnoli, namely a small section of the metropolitan branch which passes through the city of Naples (see Fig. 6).

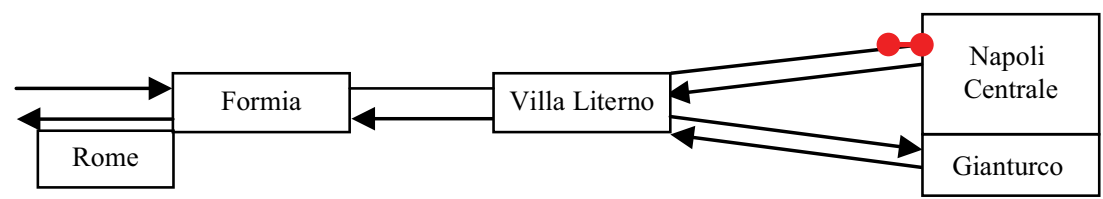

Figure 5: Graphic representation of the Scenario 2 failure.

Table 8: User generalized costs: Scenario 2 without any intervention strategy.

\begin{tabular}{lcccc}
\hline \multirow{2}{*}{ Direction of travel } & \multicolumn{3}{c}{ Service class } & \multirow{2}{*}{ Total } \\
\cline { 2 - 4 } & Intercity & Regional & Metropolitan & \\
\hline Formia-Napoli & $€ 2,753.00$ & $€ 42,849.01$ & $€ 18,423.22$ & $€ 64,025.23$ \\
Napoli-Formia & $€ 1,878.40$ & $€ 2,908.74$ & $€ 13,201.20$ & $€ 17,988,34$ \\
& & & & $€ 82,013.57$ \\
\hline
\end{tabular}

Table 9: User generalized costs: Scenario 2 with the first intervention strategy.

\begin{tabular}{lcccc}
\hline \multirow{2}{*}{ Direction of travel } & \multicolumn{3}{c}{ Service class } & \multirow{2}{*}{ Total } \\
\cline { 2 - 4 } & Intercity & Regional & Metropolitan & \\
\hline Formia-Napoli & $€ 1,447.25$ & $€ 13,611.27$ & $€ 18,423.22$ & $€ 33,481.74$ \\
Napoli-Formia & $€ 5,358.79$ & $€ 5,186.53$ & $€ 13,201.20$ & $€ 23,746.52$ \\
& & & & $€ 57,228.26$ \\
\hline
\end{tabular}


Table 10: User generalized costs: Scenario 2 with the second intervention strategy.

\begin{tabular}{lcccc}
\hline \multirow{2}{*}{ Direction of travel } & \multicolumn{3}{c}{ Service class } & \multirow{2}{*}{ Total } \\
\cline { 2 - 4 } & Intercity & Regional & Metropolitan & \\
\hline Formia-Napoli & $€ 1,446.33$ & $€ 13,014.24$ & $€ 18,423.22$ & $€ 32,883.79$ \\
Napoli-Formia & $€ 2,163.92$ & $€ 5,005.32$ & $€ 13,201.20$ & $€ 20,370.44$ \\
\hline
\end{tabular}

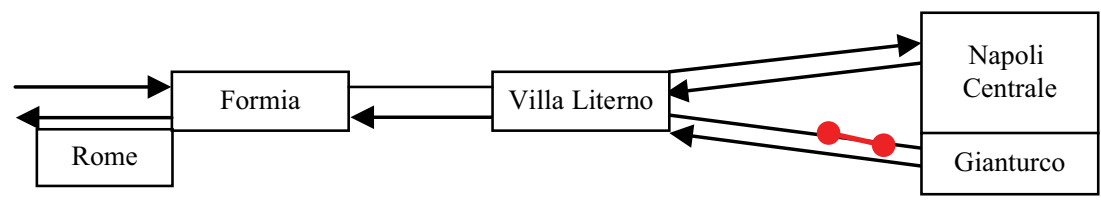

Figure 6: Graphic representation of the Scenario 3 failure.

Actually, due to the high frequency, the number of trains affected by the disruption is higher than the previous two scenarios. In addition, metropolitan trains are more crowded which is why the user generalized cost is almost three times higher than the ordinary service (see Table 11). As expected, passengers on intercity and regional trains do not perceive any increase in delay and travel time since the line between Napoli Centrale and Villa Literno is completely independent.

If the alternate circulation regime is introduced $30 \mathrm{~min}$ after the section is closed (Table 12), since the branch 'Villa Literno-Gianturco' is totally based on contra-flow tracks, there are no speed restrictions and trains can run at peak performance. As a consequence, running times remain the same in both directions and increases in generalized costs amount to $60.3 \%$ (i.e. $120.8 \%$ lower than the non-intervention strategy).

Table 11: User generalized costs: Scenario 3 without any intervention strategy.

\begin{tabular}{lcccc}
\hline \multirow{2}{*}{ Direction of travel } & \multicolumn{3}{c}{ Service class } & \multirow{2}{*}{ Total } \\
\cline { 2 - 4 } & Intercity & Regional & Metropolitan & \\
\hline Formia-Napoli & $€ 1,396.85$ & $€ 11,329.06$ & $€ 99,328.92$ & $€ 112,054.83$ \\
Napoli-Formia & $€ 1,878.40$ & $€ 2,490.36$ & $€ 20,054.60$ & $€ 24,423.36$ \\
\hline
\end{tabular}

Table 12: User generalized costs: Scenario 3 with the first intervention strategy.

\begin{tabular}{lcccc}
\hline \multirow{2}{*}{ Direction of travel } & \multicolumn{3}{c}{ Service class } & \multirow{2}{*}{ Total } \\
\cline { 2 - 4 } & Intercity & Regional & Metropolitan & \\
\hline Formia-Napoli & $€ 1,396.85$ & $€ 11,329.06$ & $€ 31,199.71$ & $€ 43,925.62$ \\
Napoli-Formia & $€ 1,878.40$ & $€ 2,490.36$ & $€ 29,528.15$ & $€ 33,896.91$ \\
\hline
\end{tabular}


Moreover, in the case of a prompt reaction (i.e. the second intervention strategy) disturbance effects are reduced especially in the case of high-frequency services where conflicts between trains arise very rapidly. Indeed, as shown in Table 13, increases in passenger delays are only $12.1 \%$ (i.e. $169.1 \%$ lower than the non-intervention strategy and $48.3 \%$ lower than the first intervention strategy).

\subsubsection{Analysis of the fourth disrupted scenario}

The disruption simulated in Scenario 4, where because of an accident involving a person, there is a four-hour interruption (i.e. from 7.00 to 11.00) of both tracks near Albanova station, is completely different. As a consequence, the infrastructure manager has to interrupt the service between Villa Literno and Napoli Centrale (see Fig. 7).

Therefore, all intercity and regional trains running through this section are forced to stop and experience considerable delay. This inconvenience is highlighted by the objective function values in Table 14, where the increase with respect to the ordinary conditions is $229.3 \%$.

As a first intervention strategy, $30 \mathrm{~min}$ after the failure event, it is hypothesized that the node in Gianturco is used to maintain the connection between Formia (or Rome via Formia) and Naples via Villa Literno, so as to satisfy most of the passenger flow. This means that, within the Villa Literno-Gianturco section, intercity, regional and metropolitan trains run all together. In addition, the trains within the section 'Villa Literno-Napoli Centrale' during the breakdown occurrence travel as far as Napoli Centrale, enabling the connection to new runs travelling on the metropolitan line.

It can be seen that the higher discomfort experienced by metropolitan passengers is compensated by the great reduction in that of intercity and regional train users (Table 15), where the total cost is still high $(+97.5 \%)$ since many commuters remain unserved for a long period especially within the Villa Literno-Napoli Centrale section.

Likewise, the second intervention strategy concerns the same rescheduling solutions which are applied immediately after section closure. In this case, the benefits provided are not so considerable (see Table 16). Indeed, the total cost decreases by only $3.7 \%$ with respect to the previous recovery plan. However, both values are much better than the non-intervention solution which, albeit optimal from an operational point of view, does not take customer needs into account, providing an increase in user delay of $131.8 \%$ and $135.6 \%$ compared to the first and second intervention strategy, respectively.

Table 13: User generalized costs: Scenario 3 with the second intervention strategy.

\begin{tabular}{lcccc}
\hline \multirow{2}{*}{ Direction of travel } & \multicolumn{3}{c}{ Service class } & \multirow{2}{*}{ Total } \\
\cline { 2 - 4 } & Intercity & Regional & Metropolitan & \\
\hline Formia-Napoli & $€ 1,396.85$ & $€ 11,329.06$ & $€ 22,720.69$ & $€ 35,446.60$ \\
Napoli-Formia & $€ 1,878.40$ & $€ 2,490.36$ & $€ 14,581.02$ & $€ 18,949.78$ \\
& & & & $€ 54,396.38$ \\
\hline
\end{tabular}

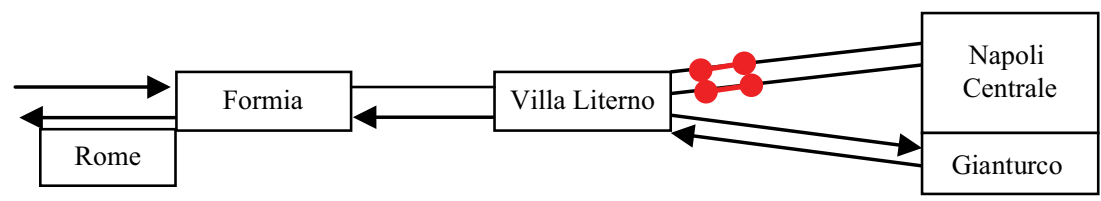

Figure 7: Graphic representation of the Scenario 4 failure. 
Table 14: User generalized costs: Scenario 4 without any intervention strategy.

\begin{tabular}{lcccc}
\hline \multirow{2}{*}{ Direction of travel } & \multicolumn{3}{c}{ Service class } & \multirow{2}{*}{ Total } \\
\cline { 2 - 4 } & Intercity & Regional & Metropolitan & \\
\hline Formia-Napoli & $€ 6,746.84$ & $€ 101,735.04$ & $€ 18,243.22$ & $€ 126,725.10$ \\
Napoli-Formia & $€ 7,716.80$ & $€ 12,207.33$ & $€ 13,201.20$ & $€ 33,125.33$ \\
& & & & $€ 159,850.43$ \\
\hline
\end{tabular}

Table 15: User generalized costs: Scenario 4 with the first intervention strategy.

\begin{tabular}{lcccc}
\hline \multirow{2}{*}{ Direction of travel } & \multicolumn{3}{c}{ Service class } & \multirow{2}{*}{ Total } \\
\cline { 2 - 4 } & Intercity & Regional & Metropolitan & \\
\hline Formia-Napoli & $€ 2,033.32$ & $€ 45,830.53$ & $€ 18,454.87$ & $€ 66,318.72$ \\
Napoli-Formia & $€ 4,270.18$ & $€ 12,135.93$ & $€ 13,132.09$ & $€ 29,538.20$ \\
& & & & $€ 95,856.92$ \\
\hline
\end{tabular}

Table 16: User generalized costs: Scenario 4 with the second intervention strategy.

\begin{tabular}{lcccc}
\hline \multirow{2}{*}{ Direction of travel } & \multicolumn{3}{c}{ Service class } & \multirow{2}{*}{ Total } \\
\cline { 2 - 4 } & Intercity & Regional & Metropolitan & \\
\hline Formia-Napoli & $€ 2,033.32$ & $€ 45,614.72$ & $€ 18,483.57$ & $€ 66,131.61$ \\
Napoli-Formia & $€ 2,363.95$ & $€ 12,066.19$ & $€ 13,481.86$ & $€ 27,912.00$ \\
& & & & $€ 94,043.61$ \\
\hline
\end{tabular}

\section{CONCLUSION AND FUTURE RESEARCH}

The aim of this article was to propose a system of models for assessing the effects on customers of different intervention solutions after the occurrence of failure events to regional rail lines. Simulation of discomfort experienced by users (i.e. waiting and running times) during their trip resulted in the evaluation of the total generalized cost of the strategy. The core of the procedure was based on a microscopic rail simulation (i.e. OPENTRACK ${ }^{\circledR}$ software) combined with a dynamic assignment tool (i.e. the OPM) for considering passenger flows within the network where typical passenger behaviour on the platform of low-frequency rail services can be faithfully simulated, providing an estimation of the generalized cost which is closer to the real phenomenon. Application on the regional 'Formia-Napoli Centrale' railway line and its metropolitan section 'Villa Literno-Gianturco' shows the effectiveness of the proposed approach for evaluating the service quality offered to passengers during degraded operation regimes.

In terms of future prospects, it would be worth combining the presented system of models with an optimization algorithm so as to overcome the limits of a what-if approach (i.e. automatically selecting a limited set of intervention strategies) and increase the computational efficiency of the whole methodology. It would also be necessary to perform sensitivity analyses of recovery solutions by means of stochastic simulations in order to enhance the feasibility of the outputs provided. 


\section{REFERENCES}

[1] Cacchiani, V., Huisman, D., Kidd, M., Kroon, L., Toth, P., Veelenturf, L. \& Wagenaar, J., An overview of recovery models and algorithms for real-time railway rescheduling. Transportation Research Part B, 63, pp. 15-37, 2014. DOI: 10.1016/j.trb.2014.01.009.

[2] D'Ariano, A. \& Albrecht, T., Running time re-optimization during real-time timetable perturbations. WIT Transactions on the Built Environment, 88, pp. 531-540, 2006. DOI: $10.2495 / C R 060531$.

[3] D’Ariano, A., Pranzo, M. \& Hansen, I.A., Conflict resolution and train speed coordination for solving real-time timetable perturbations. IEEE Transactions on Intelligent Transportation Systems, 8(2), pp. 208-222, 2007. DOI: 10.1109/TITS.2006.888605.

[4] D'Ariano, A., Improving Real-Time Train Dispatching: Models, Algorithms and Applications. PhD thesis, Delft University of Technology, The Netherlands, 2008.

[5] Goverde, R.M.P., Railway timetable stability analysis using max-plus system theory. Transportation Research Part B, 41(2), pp. 179-201, 2007. DOI: 10.1016/j.trb.2006. 02.003 .

[6] Goverde, R.M.P., A delay propagation algorithm for large-scale railway traffic networks. Transportation Research Part C, 18(3), pp. 269-287, 2010. DOI: 10.1016/j.trc.2010. 01.002 .

[7] Corman, F., D’Ariano, A., Pacciarelli, D. \& Pranzo, M., Evaluation of a green wave policy in real-time railway traffic management. Transportation Research Part $C, \mathbf{1 7}(\mathbf{6})$, pp. 607-616, 2009. DOI: 10.1016/j.trc.2009.04.001.

[8] Corman, F., D’Ariano, A., Pacciarelli, D. \& Pranzo, M., A tabu search algorithm for rerouting trains during rail operations. Transportation Research Part B, 44(1), pp. 175-192, 2010. DOI: 10.1016/j.trb.2009.05.004.

[9] Corman, F., D’Ariano, A., Pranzo, M. \& Hansen, I.A., Effectiveness of dynamic reordering and rerouting of trains in a complicated and densely occupied station area. Transportation Planning andTechnology,34(4),pp.341-362,2011.DOI: 10.1080/03081060.2011.577152.

[10] D'Ariano, A., Pacciarelli, D. \& Pranzo, M., A branch and bound algorithm for scheduling trains on a railway network. European Journal of Operational Research, 183(2), pp. 643-657, 2007. DOI: 10.1016/j.ejor.2006.10.034.

[11] D’Ariano, A., Corman, F., Pacciarelli, D. \& Pranzo, M., Reordering and local rerouting strategies to manage train traffic in real time. Transportation Science, 42(4), pp. 405-419, 2008. DOI: $10.1287 /$ trsc. 1080.0247 .

[12] Mascis, A. \& Pacciarelli, D., Job-shop scheduling with blocking and no-wait constraints. European Journal of Operational Research, 143(3), pp. 498-517, 2002. DOI: 10.1016/S0377-2217(01)00338-1.

[13] Quaglietta, E. Corman, F. \& Goverde, R.M.P., Impact of a stochastic and dynamic setting on the stability of railway dispatching solutions. Proceedings of the 14th IEEE Conference on Intelligent Transportation Systems (ITSC), pp. 1035-1040, 2013.

[14] Canca, D., Zarzo, A., Algaba, E. \& Barrena, E., Confrontation of different objectives in the determination of train scheduling. Procedia - Social and Behavioral Sciences, 20, pp. 302-312, 2011. DOI: 10.1016/j.sbspro.2011.08.036.

[15] Canca, D., Barrena, E., Zarzo, A., Ortega, F. \& Algaba, E., Optimal train reallocation strategies under service disruptions. Procedia - Social and Behavioral Sciences, 54, pp. 402-413, 2012. DOI: 10.1016/j.sbspro.2012.09.759.

[16] D’Acierno, L., Gallo, M., Montella, B. \& Placido, A., Analysis of the interaction between travel demand and rail capacity constraints. WIT Transactions on the Built Environment, 128, pp. 197-207, 2012. DOI: 10.2495/UT120181. 
[17] Hamdouch, Y., Ho, H.W., Sumalee, A. \& Wang, G., Schedule-based transit assignment model with vehicle capacity and seat availability. Transportation Research Part B, 45(10), pp. 1805-1830, 2011. DOI: 10.1016/j.trb.2011.07.010.

[18] Kanai, S., Shiina, K., Harada, S. \& Tomii, N., An optimal delay management algorithm from passengers' viewpoints considering the whole railway network. Journal of Rail Transport Planning \& Management, 1(1), pp. 25-37, 2011. DOI: 10.1016/j. jrtpm.2011.09.003.

[19] Zheng, Y., Zhang, Z., Xu, B. \& Wang, L., Carrying capacity reliability of railway networks. Journal of Transportation Systems Engineering and Information Technology, 11(4), pp. 16-21, 2011. DOI: 10.1016/S1570-6672(10)60128-6.

[20] Bifulco, G.N., Cantarella, G.E., De Luca, S. \& Di Pace, R., Analysis and modelling the effects of information accuracy on travellers' behaviour. Proceedings of the 14th IEEE Conference on Intelligent Transportation Systems (ITSC), Washington, DC, pp. 2098-2105, 2011.

[21] Dziekan, K. \& Kottenhoff, K., Dynamic at-stop real-time information displays for public transport: effects on customers. Transportation Research Part A, 41(6), pp. 489-501, 2007. DOI: 10.1016/j.tra.2006.11.006.

[22] Molina, E.J.E. \& Timmermans, H.J.P., Traveler expectations and willingness-to-pay for web-enabled public transport information services. Transportation Research Part $C$, 14(2), pp. 57-67, 2006. DOI: 10.1016/j.trc.2006.05.003.

[23] Paulley, N., Balcombe, R., Mackett, R., Titheridge, H., Preston, J. Wardman, M., Shires, J. \& White, P., The demand for public transport: The effects of fares, quality of service, income and car ownership. Transport Policy, 13(4), pp. 295-306, 2006. DOI: 10.1016/j.tranpol.2005.12.004.

[24] Hansen, I.A., \& Pachl. J., Railway Timetable and Traffic: Analysis, Modelling, Simulation, Eurail Press: Hamburg, Germany, 2008.

[25] Nash, A. \& Huerlimann, D., Railroad simulation using OpenTrack. Computers in Railways, 9, pp. 45-54, 2004. DOI: 10.2495/CR040051.

[26] D’Acierno, L., Gallo, M., Montella, B. \& Placido, A., The definition of a model framework for managing rail systems in the case of breakdowns. Proceedings of the 16th IEEE Conference on Intelligent Transportation Systems (ITSC), The Hague, pp. 1059-1064, 2013.

[27] MVA Consultancy, Understanding the Passenger: Valuation of Overcrowding on Rail Services. Report for Department of Transport, London, 2008.

[28] CENELEC, Railway Applications - Specification and Demonstration of Reliability, Availability, Maintainability and Safety (RAMS). EN50126, 1999.

[29] Pachl, J., Railway Operation and Control. VTD Rail Publishing: Mountlake Terrace, WA, 2009.

[30] Cascetta, E., Transportation Systems Analysis: Models and Applications. Springer: New York, 2009.

[31] Wardman, M. \& Whelan, G., Twenty years of rail crowding valuation studies: Evidence and lessons from British experience. Transport Reviews, 31(3), pp. 379-398, 2011. DOI: $10.1080 / 01441647.2010 .519127$. 